\title{
Large and non-specific somatic disease burdens among ageing, long-term opioid maintenance treatment patients
}

\author{
David Medved ${ }^{1,2}$, Thomas Clausen ${ }^{1}$, Anne Bukten ${ }^{1,2^{*}}\left(\mathbb{D}\right.$, Ronny Bjørnestad ${ }^{3}$ and Ashley Elizabeth Muller ${ }^{1,4}$
}

\begin{abstract}
Objectives: To describe and explore somatic disease burdens of ageing long-term patients in opioid maintenance treatment $(\mathrm{OMT})$, a unique population emerging in countries offering OMT as a long-term treatment.

Methods: We used data from the Norwegian Cohort of Patient in Opioid Maintenance Treatment and Other Drug Treatment Study (NorComt). 156 patients enrolled for at least three of the past five years provided data during structured interviews, including on chronic conditions, somatic treatment received, mental distress (SCL-25), and treatment satisfaction. A somatic disease burden was calculated from a list measuring the recent severity of 16 somatic complaints. A hierarchical multiple linear regression analysis identified correlates of somatic disease burden.

Results: Over half of patients reported at least seven somatic complaints. Reported somatic disease burden was associated with higher mental distress, more chronic conditions, fewer years in OMT, and treatment dissatisfaction. Age was unrelated, and there were few gender differences. These five variables explained $43.6 \%$ of the variance in disease burden.

Conclusion: Long-term OMT patients experience a large range of somatic complaints, and at non-acute levels. As OMT secures longevity for opioid-dependent persons, the clinical focus must be adjusted from acute to chronic care. Providers must address how to optimize health and quality of life while in treatment, as treatment may last for many years.
\end{abstract}

Keywords: Opioid maintenance treatment, Opioids, Somatic disease burden, Ageing, Chronic disease, Mental distress

\section{Introduction}

The general population is aging and so are opioid users [1]. Opioid use accounts for a significant amount of the global disease burden, and in 2016 there were 34 million opioid users worldwide [2]. In Norway, the gold standard treatment for opioid

\footnotetext{
* Correspondence: anne.bukten@medisin.uio.no

${ }^{1}$ Norwegian Centre for Addiction Research, Institute for Clinical Medicine, University of Oslo, Bygg 45, Ullevål sykehus, Kirkeveien 166, 0450 Oslo, Norway

${ }^{2}$ Division of Mental Health and Addiction, Oslo University Hospital, Oslo, Norway

Full list of author information is available at the end of the article
}

dependence, opioid maintenance treatment (OMT), is free and publicly provided, has no waiting lists, and is a life-long treatment for many. The mean age of OMT patients is therefore steadily increasing, while the intake of young patients is low, with nearly one third of patients now more than 50 years old [3]. The fact that the population of patients in OMT is ageing is a clear indicator of treatment stability and success $[3,4]$. One recent qualitative study has reported that many long-term OMT patients in Norway attribute their survival to an older age to OMT [5].

(c) The Author(s). 2020 Open Access This article is licensed under a Creative Commons Attribution 4.0 International License, which permits use, sharing, adaptation, distribution and reproduction in any medium or format, as long as you give appropriate credit to the original author(s) and the source, provide a link to the Creative Commons licence, and indicate if changes were made. The images or other third party material in this article are included in the article's Creative Commons licence, unless indicated otherwise in a credit line to the material. If material is not included in the article's Creative Commons licence and your intended use is not permitted by statutory regulation or exceeds the permitted use, you will need to obtain permission directly from the copyright holder. To view a copy of this licence, visit http://creativecommons.org/licenses/by/4.0/ The Creative Commons Public Domain Dedication waiver (http://creativecommons.org/publicdomain/zero/1.0/) applies to the data made available in this article, unless otherwise stated in a credit line to the data. 
In several other countries, patients entering OMT for the first time are also characterized by increasing age and more somatic comorbidities [6]; it follows that longterm patients will be those who have had their problems a long time [7]. Research has shown that mortality in this group of aging patients in OMT is more associated with comorbid somatic conditions, rather than ongoing illicit drug use [3, 8, 9]. A Norwegian comparison of 149 patients continuously in OMT with 51 "interrupters" showed a reduction in drug-related somatic problems for the continuous patients, but no difference in the amount of non-drug-related somatic problems between the two groups [10]. On one hand, this is a testament to OMT reducing illicit drug use over time. On the other hand, it speaks to the growing importance of recognizing OMT patients' additional, non-drug-related health care needs - and likely screening for and treating them at an earlier age than what is necessary in non-OMT populations.

Some of the main somatic problems previously reported for this population in Norway have been hepatitis $\mathrm{C}$, liver failure, cancer, kidney and lung disease [11, 12]. A recent Danish study reported an earlier onset of cardiovascular disease among hospitalized drug users compared to the general population [13], and it is likely that OMT patients also experience many other somatic problems at higher rates and at relatively young ages. Sexual dysfunction - a common side effect of OMT medications as well as associated with ageing - was also a common complaint among OMT patients according to a meta-analysis, although the authors noted that differences in sample ages prevented proper comparisons, and only men were included [14].

Research on the characteristics and needs of ageing and long-term OMT patients has been sparse, partly due to historically low survival rates. Another issue is that the lack of conceptual clarity hampers understanding and the measurement of long-term OMT patients' needs [15]. First, no commonly accepted definitions of "long-term" exist; in some countries, "long-term" means several months, while in Norway, OMT is intended to be a lifelong treatment. Second, "ageing", "elderly", and "older" are used interchangeably to describe patients, despite being defined as beginning from as young as 35 [16] to as old as 60. See Carew et al. [15] for a review of the numerous definitions of "old" used among this population.

With the OMT population aging, we need tailored healthcare that is adapted to their developing needs and characteristics $[12,17]$. To begin planning such services, we first need more information directly from patients about their somatic health needs.

This paper has three aims pertaining to the somatic health challenge of long-term OMT patients, with data collected from patient interviews:
1. Identify and quantify chronic somatic conditions, health care utilization and treatment satisfaction among ageing OMT patients.

2. Explore participants' overall, self-reported somatic disease burden.

3. Investigate factors associated with somatic disease burden.

\section{Methods}

\section{Participants and setting}

Cross-sectional data were drawn from the Norwegian Cohort of Patient in Opioid Maintenance Treatment and Other Drug Treatment Study (NorComt), a multicenter study involving 21 facilities across Norway providing OMT or residential treatment. NorComt methodology has been thoroughly described in earlier articles, and included three cohorts: patients entering OMT, patients entering residential drug treatment, and long-term OMT patients $[18,19]$. This analysis is the first to report on the latter cohort of long-term OMT patients. As treatment interruptions are common in OMT - even among stable, long-term patients [20] - a previous dropout was not an exclusion criterion. Rather, long-term patients were eligible if they were currently enrolled in OMT and had been enrolled for at least three of the past five years.

Data was collected through structured interviews utilizing a questionnaire. The questionnaire included numerous validated measures, self-developed measures, and measures commonly used in Norwegian health services. Previous publications of the larger NorComt project describe the questionnaire's development thoroughly $[18,19]$. The participating facilities were trained in questionnaire administration by the research team through a series of workshops and interview guides. Facility staff were instructed to invite all of their eligible long-term patients to participate. Participation rates were not consistently reported by the facilities, but the overall participation rate for the larger NorComt project (including the same facilities and staff) was $74 \%$, and participation for this subgroup is likely similar. In total, 156 long-term patients currently in OMT were interviewed during 2012-2016.

\section{Measures}

Somatic health problems and treatment involvement were self-reported through several checklists. The first list included ten chronic medical conditions relevant for ageing and/or substance-using populations, in which participants indicated whether they had the condition or if they did not know, and if they had received treatment for it in the past six months. Participants also selfreported if they had visited their general practitioner or 
another health care provider for somatic health issues in the past six months.

The second checklist included 16 somatic complaints common among chronic drug users, and including all major organ systems, based on the project leaders' clinical experience. Participants indicated the extent to which they had been bothered in the past two weeks by each complaint. Answers were presented on a 0-4 Likert scale, with 0 corresponding to "not at all", 1 "a little", 2 "moderately", 3 "a lot", and 4 "very much". A selfreported somatic disease burden variable was calculated as the sum of participants' answers within this checklist, with a range of $0-64$.

Three additional items captured participant evaluations of health status: "how satisfied are you with OMT in total?" (with three possible answers on a Likert-type scale), "how is your physical health now compared to before you entered OMT?" (three possible answers), and "how satisfied are you with your sexual functioning?" (five possible answers).

The interview questionnaire also included excerpts from the European version of the Addiction Severity Index [21] to collect substance use information. Participants reported their four most commonly used substances in the past six months from a list of 18 substances/categories. Each substance was presented with the amount of participants who reported it among their top four. Mental distress was measured by the Hopkins Symptoms Checklist-25 [22]. In the NorComt study we used a version of the SCL-25 with a composite score of $0-4$ in which scores over 1.0 indicate clinically concerning mental distress [21, 23].

\section{Analysis}

Descriptive statistics were used to report participants' health variables. Subgroup analyses were conducted by gender, as we were particularly interested in any differences in types of somatic complaints, such as sexual dysfunction. To investigate factors associated with disease burden, a hierarchical multiple linear regression analysis was performed with somatic disease burden as the dependent variable. The first block was made with age as a forced entry variable. The rest of the variables were those with significant bivariate correlations and were requested with a stepwise entry. These variables were SCL25 score, amount of chronic conditions, total years in OMT, satisfaction with OMT treatment (reversed so that "dissatisfied" $=3$ and "satisfied" $=0$ ), gender, amphetamine use, and employment/studying. All statistics were performed with SPSS version 21.

\section{Results}

There were 156 long-term OMT patients in our study, of which $59.6 \%$ were men (Table 1 ). The mean age in the group was 47.9 years (range: $31.6-64.3)$. The average length of time in OMT was 10.6 years, and ranged from 3 to 25 years. The majority were Nordic-born, single, and unemployed. Roughly one half (51.6\%) had completed secondary education or higher. The patients were prescribed buprenorphine monopreparate, buprenorphine with naloxone, or methadone. The mean daily doses of buprenorphine monopreparate were $16.8 \mathrm{mg}$ ( $S D$ 7.2), buprenorphine with naloxone $14.7 \mathrm{mg}(S D$ 6.3) and methadone $100.5 \mathrm{mg}$ (SD 37.5). The majority were prescribed methadone (57.7\%). Patients were asked to name up to four substances they used most commonly during the past six months and more than half reported using cannabis. The second and third most commonly used substances were unprescribed and prescribed benzodiazepines; when combined, benzodiazepines were the most commonly used, by $60.6 \%$ of patients. Over $90 \%$ reported smoking cigarettes in the past six months. $60.5 \%$ of the patients had a SCL-25 score of 1.00 or more, indicating clinically concerning mental distress. Differences between genders were tested, but not found significant.

\section{Chronic health conditions and health care utilization}

Almost three quarters of the patients reported having at least one specified chronic condition (Table 2). The most commonly reported chronic condition was hepatitis $\mathrm{C}$, reported by more than half (52.9\%). However, very few of the patients with hepatitis $\mathrm{C}$ had received treatment for it in the past six months $(12.2 \%)$. The second most common chronic condition was asthma (21.3\%), with over $80 \%$ of the patients with asthma receiving treatment for it. Other common conditions were high blood pressure (10.3\%), heart disease (5.8\%), chronic obstructive pulmonary disease (COPD) (7.8\%), and diabetes $(2.6 \%)$, all conditions that commonly increase in prevalence with age. For all of these conditions more than half of the patients received treatment. Three patients reported having liver cirrhosis.

$80.6 \%$ of patients had seen a general practitioner in the past six months, and over half of them had other somatic health care appointments. $61.7 \%$ reported that their physical health was better compared to before they entered OMT; one tenth reported it was unchanged, and one quarter reported their physical health as having worsened. Over $60 \%$ of the patients also reported being satisfied with OMT treatment, about 30\% were neutral, and only $7.9 \%$ were dissatisfied (Table 2 ).

When asked to evaluate their sexual functioning, almost one half $(46.1 \%)$ of the patients reported good or very good sexual functioning, while almost one third $(29.8 \%)$ of the patients reported poor or very poor sexual functioning. As shown in Supplementary Table 1, more 
Table 1 Description of 156 long-term OMT patients in Norway (NorComt study, Norway, 2012-2016)

\begin{tabular}{|c|c|c|c|}
\hline & Total N (\%) & Women N (\%) & Men N (\%) \\
\hline & $156(100)$ & $63(40.4)$ & $93(59.6)$ \\
\hline \multicolumn{4}{|l|}{ Sociodemographic variables } \\
\hline Age (mean, SD) & $47.9(7.1)$ & $46.7(6.5)$ & $48.6(7.4)$ \\
\hline Nordic-born & $150(96.2)$ & $62(98.4)$ & $88(95.7)$ \\
\hline Unmarried/without partner & $133(86.9)$ & $55(88.7)$ & $78(85.7)$ \\
\hline Employed or studying & 19 (12.2) & $5(8.1)$ & $14(15.4)$ \\
\hline Secondary education or higher & $80(51.6)$ & $28(45.2)$ & $52(55.9)$ \\
\hline \multicolumn{4}{|l|}{ Treatment variables } \\
\hline \multicolumn{4}{|l|}{ Type of OMT medication } \\
\hline Methadone & $89(57.0)$ & $38(60.3)$ & $51(54.8)$ \\
\hline Buprenorphine monopreparate & $42(26.9)$ & $16(25.4)$ & $26(28.0)$ \\
\hline Buprenorphine + naloxone & $22(14.1)$ & $6(9.5)$ & $16(17.2)$ \\
\hline Other (Morphine) & $1(0.6)$ & $1(1.6)$ & $0(0.0)$ \\
\hline Total years in OMT (mean, SD) & $10.6(3.7)$ & $11.0(3.5)$ & $10.4(3.8)$ \\
\hline \multicolumn{4}{|l|}{ Health and substance use } \\
\hline SCL25 score (mean, SD) & $1.35(0.86)$ & $1.54(0.87)$ & $1.23(0.83)$ \\
\hline \multicolumn{4}{|l|}{ Substances used, past 6 months } \\
\hline Cannabis & $83(53.2)$ & $32(50.8)$ & $51(54.8)$ \\
\hline Any benzodiazepines & 95 (60.6) & $41(65.1)$ & $54(58.1)$ \\
\hline -- Unprescribed benzodiazepines & $61(39.1)$ & $27(42.9)$ & $34(36.6)$ \\
\hline -- Prescribed benzodiazepines & $44(28.2)$ & $22(34.3)$ & $22(23.7)$ \\
\hline Amphetamines & $33(21.2)$ & $12(19.0)$ & $21(22.6)$ \\
\hline Alcohol & $26(16.7)$ & $7(11.1)$ & $19(20.4)$ \\
\hline Heroin & $26(16.7)$ & $10(15.9)$ & $16(17.2)$ \\
\hline Unprescribed OMT medicines & $4(2.6)$ & $0(0.0)$ & $4(4.3)$ \\
\hline Cocaine & $2(1.3)$ & $0(0.0)$ & $2(2.2)$ \\
\hline Ecstasy & $2(1.3)$ & $0(0.0)$ & $1(1.1)$ \\
\hline Crack & $0(0.0)$ & $0(0.0)$ & $0(0.0)$ \\
\hline LSD & $0(0.0)$ & $0(0.0)$ & $0(0.0)$ \\
\hline Any nicotine use & $147(94.2)$ & $60(95.2)$ & $87(93.5)$ \\
\hline Smoking & $142(91.0)$ & $60(95.2)$ & $82(88.2)$ \\
\hline Smokeless tobacco & $20(12.9)$ & $3(4.8)$ & $17(18.3)$ \\
\hline
\end{tabular}

The majority of the 156 long-term opioid maintenance treatment patients interviewed were unemployed, had received less than a high school education, and exhibited clinically concerning mental distress. The average length of treatment was 10.6 years. Opioids and opiates were reported by only $19.3 \%$ OMT opioid maintenance treatment

SCL25 Hopkins Symptoms Checklist-25

men reported being satisfied with their sexual functioning than women (50 and $35 \%$ respectively).

The subgroup analyses by gender revealed few differences (Supplementary Table 1). More women reported having at least one chronic condition than men $(82.5 \%$ of women compared to $66.7 \%$ of men). Women also reported having more chronic conditions (1.46 conditions on average compared to 0.99 for men). The only condition that was more prevalent among women was asthma (33.3\% compared to $12.9 \%$ among men). There were no differences in the proportion of each gender receiving treatment for a particular condition.

\section{Overall self-reported disease burden}

On a disease burden scale from 0 to 64 , the average score was 13.6 (SD 9.3). Over half of the patients reported being bothered at least "a little" by at least seven somatic complaints in the past 6 months.

Figure 1 displays each of the 16 somatic complaints, with "not at all" answers not shown. The most 
Table 2 Chronic conditions, health care utilization, and satisfaction (NorComt study, Norway, 2012-2016)

\begin{tabular}{|c|c|c|}
\hline & N (\%) & If yes, treatment past 6 mo. N (\%) \\
\hline \multicolumn{3}{|l|}{ Chronic conditions } \\
\hline Any chronic condition & $99(73.5)$ & -- \\
\hline Amount of chronic conditions (mean, SD) & $1.18(1.11)$ & -- \\
\hline Hepatitis C & $82(52.9)$ & $10(12.2)$ \\
\hline Unknown & $8(5.2)$ & -- \\
\hline Asthma & $33(21.3)$ & $28(84.8)$ \\
\hline Unknown & $8(5.2)$ & -- \\
\hline Hepatitis B & $22(14.3)$ & -- \\
\hline Unknown & $7(4.5)$ & -- \\
\hline High blood pressure & $16(10.3)$ & $9(56.3)$ \\
\hline Unknown & $12(7.7)$ & -- \\
\hline Chronic obstructive pulmonary disease & $12(7.8)$ & $7(58.3)$ \\
\hline Unknown & $8(5.2)$ & -- \\
\hline Heart diseases & $9(5.8)$ & $6(66.7)$ \\
\hline Unknown & $8(5.2)$ & -- \\
\hline Diabetes & $4(2.6)$ & $3(75.0)$ \\
\hline Unknown & $6(3.9)$ & -- \\
\hline Liver cirrhosis & $3(1.9)$ & $0(0.0)$ \\
\hline Unknown & $12(7.8)$ & -- \\
\hline HIV & $3(1.9)$ & $2(66.7)$ \\
\hline Unknown & $3(1.9)$ & -- \\
\hline Cancer & $1(0.6)$ & $0(0.0)$ \\
\hline Unknown & $9(5.8)$ & -- \\
\hline \multicolumn{3}{|l|}{ Health care utilization, past 6 months } \\
\hline Appointment with general practitioner & $126(80.6)$ & \\
\hline Other somatic health care appointment & $82(52.6)$ & \\
\hline \multicolumn{3}{|l|}{ Satisfaction } \\
\hline \multicolumn{3}{|l|}{ Overall satisfaction with OMT } \\
\hline Satisfied & $94(61.8)$ & \\
\hline Both satisfied and dissatisfied & $46(30.3)$ & \\
\hline Dissatisfied & $12(7.9)$ & \\
\hline \multicolumn{3}{|l|}{ Physical health compared to before OMT } \\
\hline Better & $95(61.7)$ & \\
\hline Same as before & $18(11.7)$ & \\
\hline Worse & $41(26.6)$ & \\
\hline \multicolumn{3}{|l|}{ Sexual functioning } \\
\hline Very good & $20(14.2)$ & \\
\hline Good & $45(31.9)$ & \\
\hline Neither good nor poor & $34(24.1)$ & \\
\hline Poor & $19(13.5)$ & \\
\hline Very poor & $23(16.3)$ & \\
\hline
\end{tabular}

Almost three quarters of the patients reported having a chronic condition More than half reported having hepatitis $\mathrm{C}$, for which only one eighth received treatment in the last six months. Most patients had seen a general practitioner in the past six months, and the majority was satisfied with OMT. A third of the patients reported having poor sexual functioning

OMT opioid maintenance treatment 


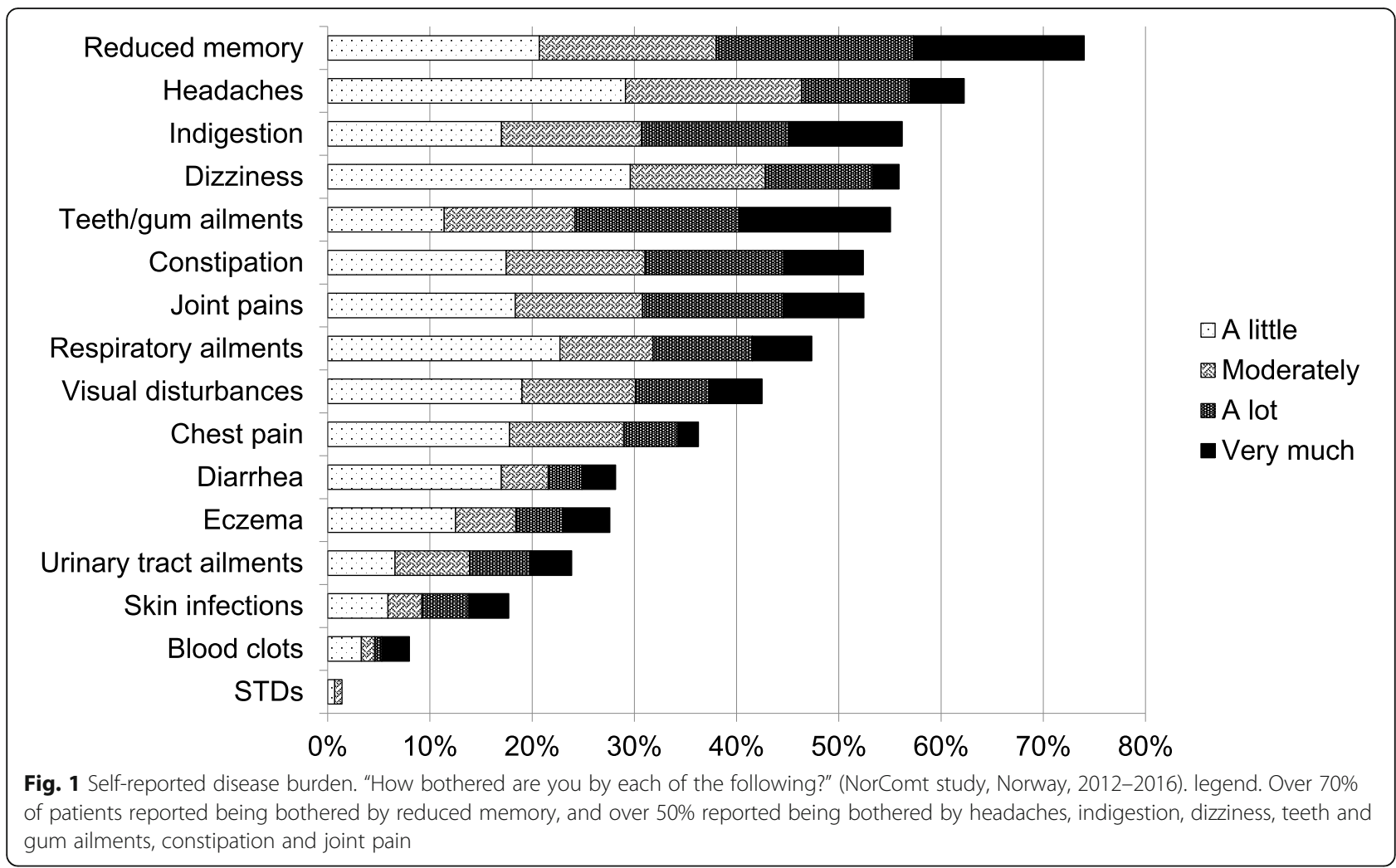

commonly reported complaint was reduced memory, with over $70 \%$ of the patients in OMT reporting being bothered at least "a little". Other complaints reported by more than half of patients were headaches, indigestion, dizziness, teeth/gum ailments, constipation and joint pains. Between 30 and $50 \%$ of patients reported having visual disturbances, respiratory ailments and chest pains. $28 \%$ reported being bothered by eczema and $18 \%$ by skin infections; $32 \%$ reported being bothered by one or both. Almost $30 \%$ of the patients were bothered by diarrhea. Eight patients reported having blood clots.

\section{Factors associated with somatic disease burden}

Five variables explained $43.6 \%$ of the variance in somatic disease burden among long-term patients in OMT (Table 3): the most explanatory variable was SCL25 score $(\beta=0.515, p<0.001)$. This variable alone explained $33.3 \%$ of the variance. The second most important variable was number of chronic conditions $(\beta=0.288, \mathrm{p}<$ 0.001 ). Total years in OMT was negatively associated to somatic disease burden $(\beta=-0.180, p=0.011)$ and dissatisfaction with OMT positively associated $(\beta=0.149$, $\mathrm{p}=0,035)$. The regression equation was significant, $\mathrm{F}(5$, $125)=21.072, p<0.001$.

\section{Discussion}

156 long-term OMT patients with an average of 10.6 years in OMT and an average age of 47.9 years reported a high prevalence of chronic somatic conditions. Three out of four had at least one chronic condition, with more than half reporting hepatitis C. Somatic disease burden analysis showed that rather than patients being highly plagued by a single somatic complaint, they were bothered by a wide range of problems on a non-acute basis. Mental distress had a strong relationship to experienced somatic disease burden.

Table 3 Adjusted models explaining variance in somatic disease burden in long-term OMT patients in Norway ${ }^{\text {. }}$ ( NorComt study, Norway, 2012-2016)

\begin{tabular}{llllll}
\hline & \multicolumn{4}{l}{ Model $^{\mathrm{b}}$} \\
\cline { 2 - 6 } & 1 & 2 & 3 & 4 & 5 \\
\hline (Constant) & --- & --- & -- & -- & \\
Age & 0.020 & 0.042 & 0.025 & 0.080 & 0.104 \\
SCL25 score & & $0.586^{* *}$ & $0.538^{* *}$ & $0.562^{* *}$ & $0.515^{* *}$ \\
Number of chronic condition & & & $0.266^{* *}$ & $0.278^{* *}$ & $0.288^{* *}$ \\
Total years in OMT & & & & $-0.174^{*}$ & $-0.180^{*}$ \\
Dissatisfaction with OMT & & & & & $0.149^{*}$ \\
Adjusted R & & & & & \\
\hline
\end{tabular}

Five variables explained $43.6 \%$ of the variance in somatic disease burden in long-term OMT patients. SCL25 score alone explained a third of the variance. Total years in OMT was a negative predictive factor

${ }^{*} p<0.05,{ }^{* *} p<0.001$

${ }^{\mathrm{a}} \mathrm{N}=131$

${ }^{b}$ Significant bivariate variables not included in adjusted models: gender, amphetamine use, employment/studying 
Few studies have targeted long-term OMT patients, and those that have, have focused on the socioeconomic outcomes of treatment [24-26]. More common are studies about "elderly" patients, using a variety of cut-off and definitions of elderly and old [15]. Studies that compared older to younger patients have reported that older patients have a higher prevalence of mobility and sight problems [1], cardiovascular, gastrointestinal, and joint problems [27], and diabetes and liver disease [28]. Our study suggests that long-term OMT patients, even those younger than the ones in the previous studies, also suffer from a range of somatic problems. Sexual dysfunction, reported by $30 \%$ of our patients, may also be experienced by OMT patients at lower ages than non-OMT populations [29].

The self-reported disease burden represents a unique indicator of somatic complaints that long-term OMT users experience in their daily lives. The low score, but high amount of complaints, indicates that most patients were not highly plagued by one specific complaint or organ system. Rather than experiencing distinctly agerelated problems or opioid-related problems, for example, their disease burdens were non-specific and varied on a group level. Low-level somatic complaints can accumulate and affect patients' quality of life (perhaps more than serious single chronic condition which may be asymptomatic for years), and it is important for clinicians not to overlook these somatic complaints and to provide treatment and relief when appropriate. It is also important to keep in mind that some of these somatic complaints might be medication side effects.

Clinically concerning mental distress was strongly correlated to the experience of somatic disease burden. The association between anxiety, depression, and somatic complaints is well documented in the general population [30]. While psychiatric problems among OMT patients have been extensively reported [31-33], distress may also be heightened due to stigma, as recently reported in a similarly aged sample of Taiwanese OMT patients [34] and among others with substance use disorders [35]. Ageing patients in particular may experience stigma both from health care providers because they are drug users, and from other drug users because they are older or in OMT [11, 36, 37]. Such stigma may contribute to mistrust of and hesitation about using health care services [36], which in turn could explain the connection with a higher somatic disease burden. These relationships needs further investigating.

Patients had recently received treatment (56-84\%) for most of their chronic conditions and the majority of the sample reported recent contact with some form of somatic health services. Given that this group of patients is in near constant contact with OMT services, we perhaps should be able to expect even higher rates of treatment for chronic conditions. At the same time, a six-month period might be too short of a window to capture those who need such treatment currently. Hepatitis $C$ is a notable exception, and there is clearly potential for great improvement. Only one of every eight patients with hepatitis $\mathrm{C}$ had recently received treatment. One explanation for low uptake in our group might be that, due to an average age of only 49, they have not yet experienced the full complications of hepatitis $C$ that can take decades to develop, such as liver cirrhosis, which was reported by less than 2\%. Another explanation could be that the current gold standard, a 12-week treatment with direct-acting antiviral agents [38], was not yet available at the time of data collection. While all patients in OMT should be screened for hepatitis C, $5 \%$ of the patients in our sample still reported not knowing their hepatitis $\mathrm{C}$ status, even after at least three years in treatment.

Satisfaction rates with OMT were as high as those typically found in OMT patient satisfaction surveys [39], and predicted a lower somatic disease burden. High satisfaction is an important indicator of treatment outcome, but attention should also be paid to those who are dissatisfied, who may still have a higher risk of dropping out, even after many years in treatment. The experience of somatic complaints or medication side-effects may be a cause of treatment discontinuation, as reported in an early methadone study [40] and more recently among a prison sample [41]. This needs to be further explored, beginning by being continuously monitored by clinicians. User representatives can have important roles to play in aggregating patient feedback - perhaps especially feedback seen as negative, such as certain side-effects or dissatisfaction with treatment - as well as in helping clinicians decide how best to collect such feedback [42].

\section{Strengths and limitations}

While a convenience sample, this sample shared many sociodemographic and treatment-related characteristics as the national OMT population [3] and as a peer-topeer survey of 1011 patients in Norway conducted in the same time period [43]. This lends confidence to the generalization of our results to the long-term patient population as a whole, which is particularly encouraging given that participation rates were not reported by the interviewing facilities. Nevertheless, a cross-sectional design limits any firm claims of causality, and a confounder not captured by the questionnaire - such as years of drug use before enrolling into OMT - may better explain somatic disease burden than the variables in the regression model. Patients who agreed to participate may be more satisfied, and potentially less somatically burdened, than those who declined. Patients' self-reports might have also been underestimates of chronic conditions. If true, the larger long-term OMT population may have an even higher somatic burden than observed. The 
relatively small sample size makes it difficult to identify significant associations between variables, and a larger size is needed in the future in order to explore subgroups such as gender. This was an exploratory analysis with many post hoc tests of association between the candidate predictor variables and somatic disease burden. As there was no control of Type I error rate, the chance of Type I error is inflated.

Finally, collecting patient-reported somatic complaints rather than clinical indicators is a novel technique that allowed us to construct a self-reported disease burden measure which provides information on the lived experiences of somatic problems. The main limitation to this technique is that the scale was locally developed and therefore the sample's somatic disease burden cannot be directly compared to existing research. Future assessment of the scale's measurement properties using data from the larger NorComt study is planned.

\section{Conclusion}

Long-term OMT patients are a population that is likely experiencing more somatic health problems and at younger ages than the general populations, which brings new challenges to the treatment system as this population ages. In order to achieve further gains in survival and in quality of life, it is important that treatment providers address their somatic health, particularly access to hepatitis C treatment. Given the prevalence of chronic conditions, long-term patients should receive regular check-ups and screenings. The responsibility and capacity of somatic health services, OMT, and geriatric services to screen, refer, and treat such diseases must first be clearly defined. It is also important to focus not only on easily diagnosable diseases, but also on the range of complaints that many patients are used to living with, including side-effects from OMT medications and mental health. Doing so may encourage treatment retention and satisfaction in addition to promoting healthy longevity. Treatment services need to refocus the services to provide for patients with chronic conditions as well as over several decades of treatment, rather than services which are primarily geared towards acute conditions and shorter timeframes.

\section{Supplementary Information}

The online version contains supplementary material available at https://doi. org/10.1186/s13011-020-00311-4.

Additional file 1: Supplementary Table 1. Chronic conditions, health care utilization, and satisfaction by gender (NorComt study, Norway, 2012-2016). legend. The subgroup analyses by gender revealed few differences in chronic conditions, treatment received, and satisfaction.

\section{Abbreviations}

NorComt: The Norwegian Cohort of Patient in Opioid Maintenance Treatment and Other Drug Treatment Study; OMT: Opioid maintenance treatment; SCL-25: The Hopkins Symptoms Checklist-25; COPD: chronic obstructive pulmonary disease

\section{Acknowledgements}

The authors wish to thank NorComt participants for their willingness to contribute to this study, and facility staff for collecting data.

\begin{abstract}
Authors' contributions
DM analyzed the dataset and drafted the manuscript. RB was a user representative and helped design the research question prior to analysis, and contributed to interpretation of results. TC was the NorComt project leader and contributed to drafting the manuscript and interpreting the results. $A B$ also contributed to designing the paper and to the discussion. AEM was the primary supervisor in the process of writing this manuscript. All authors read and approved the final manuscript.
\end{abstract}

Funding

The study did not receive any specific funding

Availability of data and materials

Data is not yet available due to ongoing analysis.

Ethics approval and consent to participate

The study was approved by The Regional Committee for Research Ethics in Norway (REK 2012/1131). Written informed consent was obtained from all study participants.

\section{Consent for publication}

Not applicable.

\section{Competing interests}

The authors declare that they have no conflicts of interest.

\section{Author details}

${ }^{1}$ Norwegian Centre for Addiction Research, Institute for Clinical Medicine, University of Oslo, Bygg 45, Ullevål sykehus, Kirkeveien 166, 0450 Oslo, Norway. ${ }^{2}$ Division of Mental Health and Addiction, Oslo University Hospital, Oslo, Norway. ${ }^{3}$ proLAR, Søgne, Norway. ${ }^{4}$ Division of Health Services, Norwegian Institute of Public Health, Oslo, Norway.

Accepted: 28 August 2020

Published online: 16 November 2020

References

1. Han B, Polydorou S, Ferris R, Blaum CS, Ross S, McNeely J. Demographic trends of adults in New York City opioid treatment programs--an aging population. Subst Use Misuse. 2015;50(13):1660-7.

2. UNODC. Executive summary: Conclusions and policy implications. United Nations Office on Drugs and Crime; 2018. Contract No.: 13. 08. 2018.

3. Waal H, Bussesund K, Clausen T, Skeie I, Lillevold PH. Status raport 2017: LAR 20 år - Status, vurdering og perspektiver [Status report 2017: OMT 20 years Status, review and perspektives]. Oslo: Senter for rus- og

avhengighetsforskning, Nasjonal kompetansetjeneste for tverrfaglig spesialisert rusbehandling; 2018. Contract No.: 3/2018.

4. Clausen T, Anchersen K, Waal H. Mortality prior to, during and after opioid maintenance treatment (OMT): a national prospective cross-registry study. Drug Alcohol Depend. 2008;94(1-3):151-7.

5. Nyhagen HT, Waal H. Den aldrende LAR pasienten. Nordic Stud Alcohol Drugs. 2017;34(1):72-9.

6. Sharif B, Nosyk B, Sun H, Marsh DC, Anis A. Changes in the characteristics and levels of comorbidity among new patients into methadone maintenance treatment program in British Columbia during its expansion period from 1998-2006. Subst Use Misuse. 2013:48(8):671-82.

7. Waal H, Bussesund K, Clausen T, Skeie I, Håseth A, Lillevold PH. Statusrapport 2014: En aldrende LAR-populasjon? [OMT Status Report 2014: An aging OMT population?]. Oslo: Senter for rus- og avhengighetsforskning, og Nasjonal kompetansetjeneste for tverrfaglig spesialisert rusbehandling; 2015. Contract No.: 2015/2.

8. Waal H, Bussesund K, Clausen T, Skeie I, Håseth A, Lillevold PH. Statusrapport 2016: Er kvalitetsforbedring nå viktigere enn kapasistetsutvikling? [OMT Status report 2016: Is now the improvement of quality more important than 
capacity development?]. Oslo: Senter for rus- og avhengighetsforskning, and Nasjonal kompetansetjeneste for tverrfaglig spesialisert rusbehandling; 2017. Contract No:: 2/2017.

9. Gao L, Robertson JR, Bird SM. Non drug-related and opioid-specific causes of 3262 deaths in Scotland's methadone-prescription clients. Drug Alcohol Depend. 2009-2015:2019.

10. Skeie I, Brekke M, Clausen T, Gossop M, Lindbaek M, Reinertsen E, et al. Increased somatic morbidity in the first year after leaving opioid maintenance treatment: results from a Norwegian cohort study. Eur Addict Res. 2013;19(4):194-201.

11. Doukas N. Older adults in methadone maintenance treatment: a literature review. J Soc Work Pract Addict. 2011;11(3):230-44

12. Gaulen Z, Alpers S, Carlsen S, Nesvåg S. Health and social issues among older patients in opioid maintenance treatment in Norway. Nordic Stud Alcohol Drugs. 2017;34(1):80-90.

13. Thylstrup B, Clausen T, Hesse M. Cardiovascular disease among people with drug use disorders. Int J Public Health. 2015;60(6):659-68.

14. Yee A, Loh HS, Hisham Hashim HM, Ng CG. The prevalence of sexual dysfunction among male patients on methadone and buprenorphine treatments: a meta-analysis study. J Sex Med. 2014;11(1):22-32.

15. Carew AM, Comiskey C. Treatment for opioid use and outcomes in older adults: a systematic literature review. Drug Alcohol Depend. 2018; 182:48-57.

16. People TEWGoO, With a drug problem. Older people with drug problems in Scotland: addressing the needs of an ageing population. Scottish drugs form; 2017. Contract No: Final Report.

17. Dürsteler-MacFarland KM, Vogel M, Wiesbeck GA, Petitjean SA. There is no age limit for methadone: a retrospective cohort study. Subst Abuse Treat Prev Policy. 2011;6:9.

18. Muller AE, Skurtveit $\mathrm{S}$, Clausen T. Many correlates of poor quality of life among substance users entering treatment are not addiction-specific. Health Qual Life Outcomes. 2016;14:39.

19. Skjaervo I, Skurtveit S, Clausen T, Bukten A. Substance use pattern, selfcontrol and social network are associated with crime in a substance-using population. Drug and alcohol review. 2017;36(2):245-52.

20. Soyka M, Strehle J, Rehm J, Buhringer G, Wittchen HU. Six-year outcome of opioid maintenance treatment in heroin-dependent patients: results from a naturalistic study in a nationally representative sample. Eur Addict Res. 2017;23(2):97-105.

21. Ravndal E, Lauritzen G. Opiate users in methadone-assisted rehabilitation one year and two years after admission. Tidsskrift for den Norske laegeforening : tidsskrift for praktisk medicin, ny raekke. 2004;124(3):329-31.

22. Derogatis LR, Lipman RS, Rickels K, Uhlenhuth EH, Covi L. The Hopkins symptom checklist (HSCL): a self-report symptom inventory. Behav Sci. 1974; 19(1):1-15.

23. Lund IO, Skurtveit S, Sarfi M, Bakstad B, Welle-Strand G, Ravndal E. A 2-year prospective study of psychological distress among a national cohort of pregnant women in opioid maintenance treatment and their partners. J Subst Abus. 2013;18(2):148-60.

24. Appel P, Joseph H, Nottingham W, Tasiny E, Habel E. Selected in-treatment outcomes of long-term methadone Maintenace treatment patients in New York state. The Mount Sinai Journal of Medicine. 2001;68(1):55-61.

25. Guttinger F, Gschwend P, Schulte B, Rehm J, Uchtenhagen A. Evaluating long-term effects of heroin-assisted treatment: the results of a 6-year followup. Eur Addict Res. 2003;9(2):73-9.

26. Novick DM, Richman BL, Friedman JM, Friedman JE, Fried C, Wilson JP, et al. The medical status of methadone maintenance patients in treatment for 11-18 years. Drug Alcohol Depend. 1993;33(3):235-45.

27. Lofwall MR, Brooner RK, Bigelow GE, Kindbom K, Strain EC. Characteristics of older opioid maintenance patients. J Subst Abus Treat. 2005;28(3):265-72.

28. Firoz S, Carlson G. Characteristics and treatment outcome of older methadone-maintenance patients. Am J Geriatr Psychiatry. 2004;12(5):539-41.

29. Englert $H$, Schaefer $G$, Roll S, Ahlers C, Beier K, Willich S. Prevalence of erectile dysfunction among middle-aged men in a metropolitan area in Germany. Int J Impot Res. 2007;19(2):183-8.

30. Haug TT, Mykletun A, Dahl AA. The association between anxiety, depression, and somatic symptoms in a large population: the HUNT-II study. Psychosom Med. 2004;66(6):845-51.

31. Rosic T, Naji L, Bawor M, Dennis BB, Plater C, Marsh DC, et al. The impact of comorbid psychiatric disorders on methadone maintenance treatment in opioid use disorder: a prospective cohort study. Neuropsychiatr Dis Treat. 2017;13:1399-408.
32. Hser Yl, Evans E, Grella C, Ling W, Anglin D. Long-term course of opioid addiction. Harvard review of psychiatry. 2015;23(2):76-89.

33. Carpentier PJ, Krabbe PF, van Gogh MT, Knapen LJ, Buitelaar JK, de Jong CA. Psychiatric comorbidity reduces quality of life in chronic methadone maintained patients. Am J Addict. 2009;18(6):470-80.

34. Chang K-C, Lin C-Y, Chang C-C, Ting S-Y, Cheng C-M, Wang J-D. Psychological distress mediated the effects of self-stigma on quality of life in opioid-dependent individuals: a cross-sectional study. PLoS One. 2019; 14(2):e0211033.

35. Melchior H, Husing P, Grundmann J, Lotzin A, Hiller P, Pan Y, et al. Substance abuse-related self-stigma in women with substance use disorder and comorbid posttraumatic stress disorder. Eur Addict Res. 2019;25(1):20-9.

36. Rosen D, Hunsaker A, Albert SM, Cornelius JR, Reynolds CF 3rd. Characteristics and consequences of heroin use among older adults in the United States: a review of the literature, treatment implications, and recommendations for further research. Addict Behav. 2011;36(4):279-85

37. Conner KO, Rosen D. "You're nothing but a junkie": multiple experiences of stigma in an aging methadone maintenance population. J Soc Work Pract Addict. 2008;8(2):244-64

38. Trabut JB, Barrault C, Charlot H, Carmona D, Bourdel A, Benslimane M, et al. Integrated Care for the use of direct-acting antivirals in patients with chronic hepatitis C and substance use disorder. J Addict Med. 2018.

39. Trujols J, Iraurgi I, Oviedo-Joekes E, Guardia-Olmos J. A critical analysis of user satisfaction surveys in addiction services: opioid maintenance treatment as a representative case study. Patient Prefer Adherence. 2014;8: 107-17.

40. Adams RG, Bloom WA, Capel WC, Stewart GT. Heroin addicts on methadone replacement: a study of dropouts. Int J Addict. 1971;6(2):269-77.

41. Vocci FJ, Schwartz RP, Wilson ME, Gordon MS, Kinlock TW, Fitzgerald TT, et al. Buprenorphine dose induction in non-opioid-tolerant pre-release prisoners. Drug Alcohol Depend. 2015;156:133-8.

42. Pettersen $H$, Brodahl M, Rundgren J, Davidson L, Havnes IA. Partnering with persons in long-term recovery from substance use disorder: experiences from a collaborative research project. Harm Reduct J. 2019;16(1):40-.

43. Muller AE, Bjornestad R, Clausen T. Dissatisfaction with opioid maintenance treatment partly explains reported side effects of medications. Drug Alcohol Depend. 2018;187:22-8.

\section{Publisher's Note}

Springer Nature remains neutral with regard to jurisdictional claims in published maps and institutional affiliations.

Ready to submit your research? Choose BMC and benefit from:

- fast, convenient online submission

- thorough peer review by experienced researchers in your field

- rapid publication on acceptance

- support for research data, including large and complex data types

- gold Open Access which fosters wider collaboration and increased citations

- maximum visibility for your research: over $100 \mathrm{M}$ website views per year

At $\mathrm{BMC}$, research is always in progress.

Learn more biomedcentral.com/submission 